\title{
APLIKASI PENJADWALAN PROGRAM PRAKTIKUM FAKULTAS TEKNOLOGI INFORMASI UNIVERSITAS ISLAM KALIMANTAN (UNISKA) MUHAMMAD ARSYAD AL BANJARI BANJARMASIN \\ Fathul Hafidh ${ }^{1}$, Muhammad Dedy Rosyadi' ${ }^{2}$ \\ ${ }^{1,2)}$ Fakultas Teknologi Informasi, Universitas Islam Kalimantan Muhammad Arsyad Al Banjari Banjarmasin Jl. Adhyaksa No.2 Kayu Tangi Banjarmasin 70123 e-mail: hafidh@fti.uniska-bjm.ac.id ${ }^{1)}$, dedy.rosyadi@gmail.com ${ }^{2}$ )
}

\begin{abstract}
ABSTRAK
Tujuan penelitian ini adalah memudahkan pelaksanaan program praktikum yang dilaksanakan di Fakultas Teknologi Informasi (FTI) Universitas Islam Kalimantan (UNISKA) Muhammad Arsyad Al Banjari Banjarmasin, yang mana adaya program praktikum dikarenakan FTI ingin meningkatkan kemampuan mahasiswa dalam keilmuan pemrograman yang berorientasi produk. Keinginan untuk memberikan kompetensi ini tidak dapat dilakukan melalui tatap muka perkuliahan seperti biasa dikarenakan semisal mata kuliah Pemrograman Web I hanya diajarkan dalam 16 (enam belas) pertemuan dan tidak berorientasi pada produk. Maka dari itu diperlukan praktikum untuk peningkatan skill pemrograman diluar dari jadwal perkuliahan yang telah ada. Target yang ingin dicapai adalah membuat aplikasi yang membantu dalam pendaftaran mahasiswa yang akan mengikuti kelas praktikum, membantu dosen dalam memanajemen jadwal praktikum, mencetak daftar hadir kelas praktikum dan membantu agar dosen dan mahasiswa dapat membuat dan memilih jadwal yang tidak bertabrakan dengan jadwal perkuliahan.
\end{abstract}

Kata Kunci : Aplikasi, Penjadwalan, Program Praktikum.

The purpose of this research is to facilitate the implementation of the practicum program implemented in the Faculty of Information Technology (FTI) of Islamic University of Borneo (UNISKA) Muhammad Arsyad Al Banjari Banjarmasin, where there is a practicum program because FTI wants to improve students' skills in product-oriented programming science. The desire to provide this competency can not be done through face-to-face lectures as usual because the course of Web Programming I is only taught in 16 (sixteen) meetings and is not product-oriented. Therefore it is necessary practice to increase the skill of programming outside of existing lecture schedule. Target to be achieved is to make an application that helps in the enrollment of students who will follow the class practicum, assisting lecturers in managing the lab schedule, print the attendance list of practical classes and help lecturers and students can create and choose schedules that do not collide with lecture schedule.

Keywords: Application, Scheduling, Practicum Program.

\section{PENDAhuluan}

KOMPETENSI mahasiswa pada perguruan tinggi merupakan indikator penting dalam menentukan kemampuan mahasiswa dan kesuksesan perguruan tinggi untuk mencapai visi dan misi dari Universitas Islam Kalimantan (UNISKA) Muhammad Arsyad Al Banjari Banjarmasin, yaitu "Universitas yang unggul dalam kecerdasan intelektual, emosional dan spiritual yang menekankan pada pengembangan ilmu pengetahuan, teknologi, seni dan ilmu keIslaman, serta pelestarian dan pengkayaan budaya bangsa yang Islami”.

Pada Fakultas Teknologi Informasi, salah satu kompetensi mahasiswa yang menjadi perhatian khusus adalah kemampuan mahasiswa dalam ilmu pemrograman yang berorientasi produk. Keinginan untuk memberikan kompetensi ini tidak dapat dilakukan melalui tatap muka perkuliahan seperti biasa dikarenakan semisal mata kuliah Pemrograman Web I hanya diajarkan dalam 16 (enam belas) pertemuan dan tidak berorientasi pada produk. Maka dari itu diperlukan praktikum untuk peningkatan skill pemrograman diluar dari jadwal perkuliahan yang telah ada.

Selama ini pelaksanaan praktikum keahlian pemrograman telah dilaksanakan pada setiap semester, hanya saja angka keikutsertaan mahasiswa masih sangat minim. Rata-rata mahasiswa yang mengikuti program praktikum ini hanya $45 \%$ dari total mahasiswa. Hal ini disebabkan pelaksanaan jadwal praktikum yang kurang jelas, waktu pendaftaran praktikum yang terlalu pendek dan kurangnya publikasi terkait jadwal pelaksanaan praktikum tersebut. 
Kompleksitas penjadwalan praktikum di FTI UNISKA Banjarmasin terjadi pada banyaknya jumlah mahasiswa aktif, berdasarkan data portal akademik UNSIKA Banjarmasin, pada tahun akademik 2016/2017 semester Genap total mahasiswa aktif Fakultas Teknologi Informasi sebanyak 3.057 mahasiswa, dengan rincian sebanyak 2.879 orang mahasiswa program studi Teknik Informatika dan 178 orang mahasiswa program studi Sistem Informasi. Setiap instruktur (Pengajar/Dosen) dari Praktikum yang diampu membuat jadwal praktikum sesuai keinginan Instruktur yang mana menyesuaikan ketersediaan waktu sehingga tidak bertabrakan dengan jadwal yang lebih utama yaitu pelaksanaan perkuliahan.

Seiring dengan perkembangan teknologi terdapat tuntutan terciptanya inovasi-inovasi baru yang mendukung terciptanya sistem yang dapat menyelesaikan permasalahan pada penjadwalan praktikum. Penelitian ini akan menyelesaikan permasalahan; 1). Pendaftaran dan pendataan peserta praktikum masih manual, 2). Kurangnya pengetahuan mahasiswa terhadap jadwal pelaksanaan praktikum, 3). Jadwal praktikum yang dibuat dosen sering kali bertabrakan dengan jadwal perkuliahan, 4). Absensi peserta praktikum memerlukan pekerjaan cukup lama karena memilih dari pendaftaraan secara manual lalu mengetik ulang ke dalam jadwal yang dibuat dosen.

Dengan berbagai permasalahan tersebut, Sanjaya [1] membuat Aplikasi Sistem Penjadwalan pada STMIK AUB Surakarta yang dapat menjadwalkan hari perkuliahan, dosen, mata kuliah, ruang dan waktu dari semua program studi mampu membuat jadwal yang tersusun rapi tanpa bertabrakan antara jadwal yang ada. Kemudian, terdapat pula Sistem Informasi Penjadwalan Dosen Ajar Studi Kasus : STMIK Atma Luhur [2] yang membuat rancangan sistem informasi dapat menghasilkan laporan yang cepat, akurat dan efisien serta dapat meningkatkan kinerja karyawan pada STMIK Atma Luhur Pangkalpinang. Berdasarkan kedua literature tersebut maka penelitian ini menghasilkan aplikasi yang dapat membantu menyelesaikan permasalahan yang ada saat ini. Aplikasi Penjadwalan Program Praktikum yang akan dibangun dapat membantu pendaftaran dan pendataan mahasiswa yang akan mengikuti kelas praktikum, membantu dosen dalam memanajemen jadwal praktikum, mampu mencetak daftar hadir kelas praktikum dan membantu agar dosen dan mahasiswa dapat membuat dan memilih jadwal yang tidak bertabrakan dengan jadwal perkuliahan.

\section{LANDASAN TEORI}

\section{A. Penjadwalan}

Penjadwalan oleh Reksohadiprojo, 1994, didefiniskan sebagai suatu proses yang dinamis yang merupakan bagian dari fungsi pengawasan produksi yang menentukan waktu kapan setiap kegiatan harus dilaksanakan pada mesin tertentu agar waktu pengiriman produk dapat terpenuhi. Sedangkan Kenneth. R. Baker menyatakan bahwa penjadwalan adalah suatu proses pengalokasian sumber daya untuk memilih sekumpulan job dalam jangka waktu tertentu. Dalam definisi tersebut terdapat dua pengertian yaitu penjadwalan sebagai suatu fungsi pengambilan keputusan yang berkaitan dengan penentuan proses yang akan dijadwalkan dan penjadwalan sebagai teori dengan prinsip, model teknik dan logika kesimpulan yang dapat membuktikan secara jelas kedalaman fungsi dari penjadwalan itu sendiri [3].

\section{B. Aplikasi}

Software yang memproses data untuk pengguna. Terkecuali untuk "perangkat lunak sistem," yang menyediakan infrastruktur di komputer (sistem operasi, utilitas dan komponen terkait), semua program perangkat lunak adalah program aplikasi.Di dunia hiburan, aplikasi mengacu pada game. Di dunia bisnis, ini mengacu pada data entry, update, query dan laporan program.Istilah aplikasi mungkin juga mengacu pada aplikasi generik, yang sering disebut "program produktivitas", seperti browser Web, spreadsheet, pengolah kata, database atau program e-mail [4].

\section{PHP}

PHP adalah akronim dari Hypertext Preprocessor, yaitu suatu bahasa pemrograman berbasiskan kode-kode (script) yang digunakan untuk mengolah suatu data dan mengirimkannya kembali ke web browser menjadi kode HTML [5]. Kode PHP memiliki ciri-ciri khusus yaitu :

1. Hanya dapat dijalankan menggunakan web server, misal : Apache.

2. Kode PHP diletakkan dan dijalankan di web server.

3. Kode PHP dapat digunakan untuk mengakses database, seperti : MySQL, Oracle dan lain-lain.

4. Merupakan Software yang bersifat Open Source.

5. Memiliki sifat Multiplatform, artinya dapat dijalankan menggunakan sistem operasi apapun, seperti: Linux, Windows, Android dan lain-lain. 
Hafidh, Rosyadi — Aplikasi Penjadwalan Program Praktikum Fakultas Teknologi Informasi Universitas Islam Kalimantan (UNISKA) Muhammad Arsyad Al Banjari Banjarmasin

\section{Metode Penelitian}

Metode penelitian yang dilakukan adalah metode penelitian eksperimen, dengan tahapan penelitian seperti berikut:

\section{A. Analisa Kebutuhan}

Analisa kebutuhan pada penelitian ini dibagi dua menjadi pengumpulan data dan metode pengolahan data.

\section{B. Metode Pengumpulan Data}

Metode pengumpulan data yang digunakan dalam penelitian ini adalah :

a. Wawancara

Metode pengumpulan data dengan cara mengadakan tanya jawab yang dilakukan secara langsung pada di Universitas Islam Kalimantan (UNISKA) Muhammad Arsyad Al Banjari Banjarmasin pada Fakultas Teknologi Informasi .

b. Observasi

Pengumpulan data melalui pengamatan dan pencatatan terhadap data persediaan yang berkaitan dengan objek penelitian. Pengamatan dilakukan langsung secara observasi di Universitas Islam Kalimantan (UNISKA) Muhammad Arsyad Al Banjari Banjarmasin pada Fakultas Teknologi Informasi

c. Studi Pustaka

Pengumpulan data dengan membaca serta mempelajari dokumen-dokumen, literatur, jurnal, dan bukubuku serta sumber lain yaitu internet yang berhubungan dengan pembuatan laporan.

\section{Metode Pengolahan Data}

Dalam penelitian ini sampel data yang digunakan adalah data kegiatan praktikum berupa data dosen, data mahasiswa, dan data jadwal kegiatan praktikum.

\section{Analisis Kebutuhan Sistem}

Analisis Kebutuhan merupakan tahap pengumpulan data-data yang diperlukan untuk digunakan sebagai dasar pegembangan sistem informasi. Anlasisis kebutuhan yang digunakan berupa : studi lapangan (observasi), pengumpulan sumber-sumber materi (studi pustaka) dan pencarian penelitian yang relevan. Adapun usulan sistem yang berkembang adalah sebagai berikut:

1. Sistem mampu membantu pendaftaran dan pendataan peserta yang mengikuti program praktikum pada FTI UNISKA Banjarmasin

2. Sistem mampu menjadi media publikasi pelaksanaan program praktikum.

3. Sistem mampu memanajemen penjadwalan program praktikum.

4. Laporan yang dikeluarkan dari aplikasi ini seperti laporan data mahasiswa, laporan data absen praktikum, lapran data pelaksanaan praktikum, laporan data pelaksanaan.

5. Data Flow Diagram dapat dilihat pada Gambar 1.

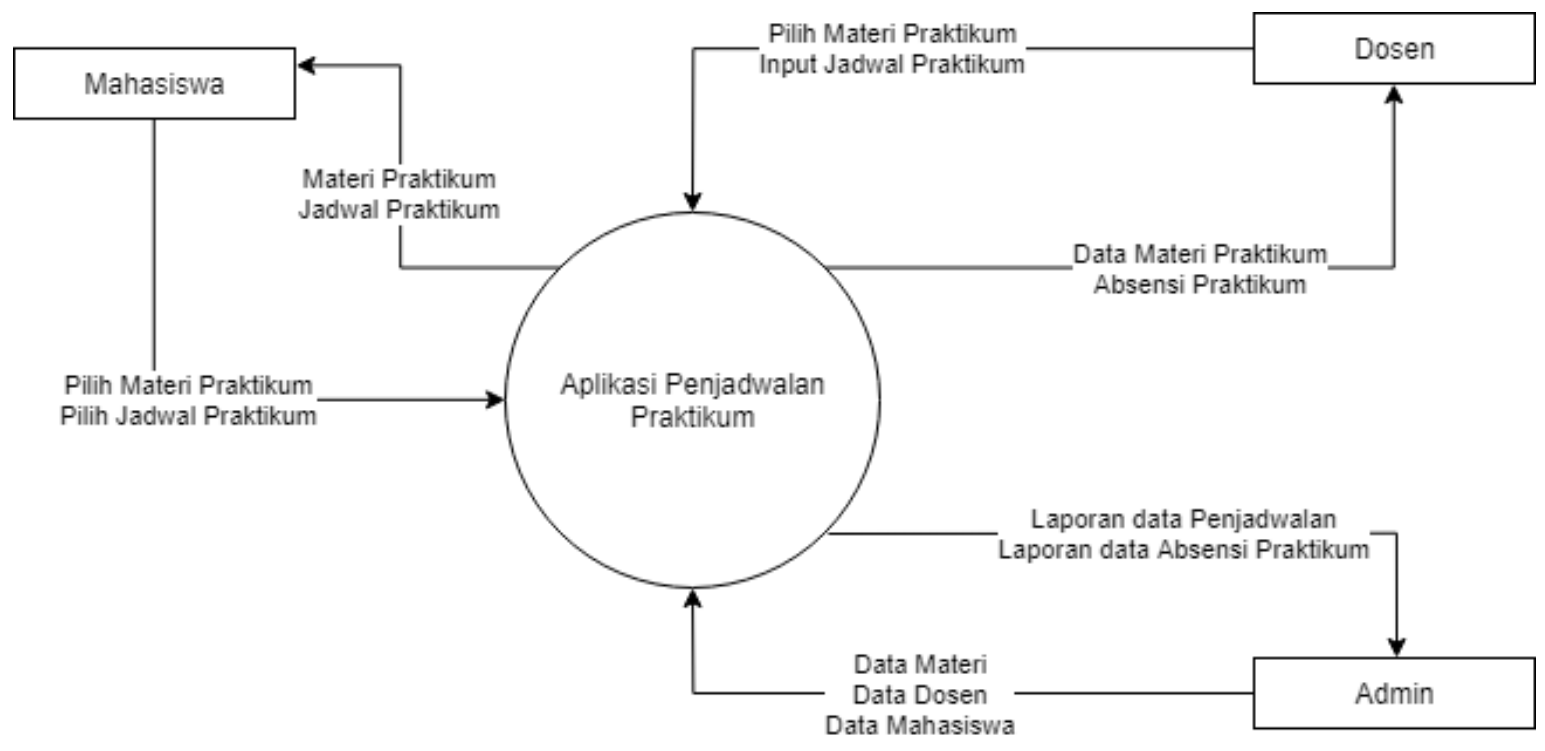

Gambar. 1. DFD level 0 


\section{ANALISA HASIL DAN PEMBAHASAN}

\section{A. Hasil Penelitian}

Aplikasi dibangun sesuai kebutuhan sistem agar mempermudah seluruh user yang menggunakan sistem tersebut, terdapat empat (4) bagian yaitu:

\section{Halaman Utama}

Pada halaman depan terdapat informasi berita berupa pengumuman pelaksanaan dan hal-hal lain terkait kegiatan praktikum. Terdapat album gambar (galery) sebagai dokumentasi kegiatan praktikum yang telah dilaksanakan. Tampilan halaman utama ditunjukkan oleh Gambar 2.

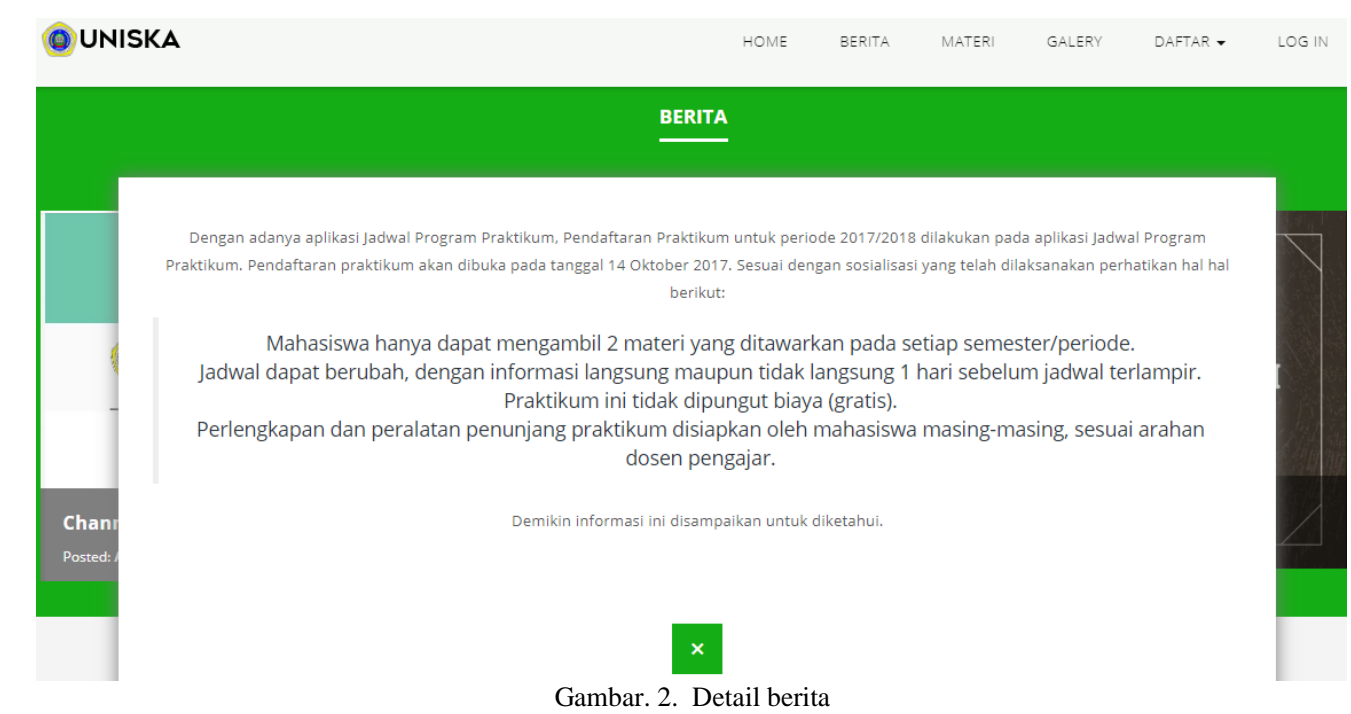

\section{Login Mahasiswa}

Mahasiswa memiliki fitur-fitur halaman seperti halaman materi praktikum, untuk menampilkan materi yang ingin diambil oleh mahasiswa seperti ditunjukkan oleh Gambar 3. Kemudian jadwal terlampir untuk diikuti. Juga terdapat halaman Jadwal Saya untuk melihat jadwal yang telah dipilih.

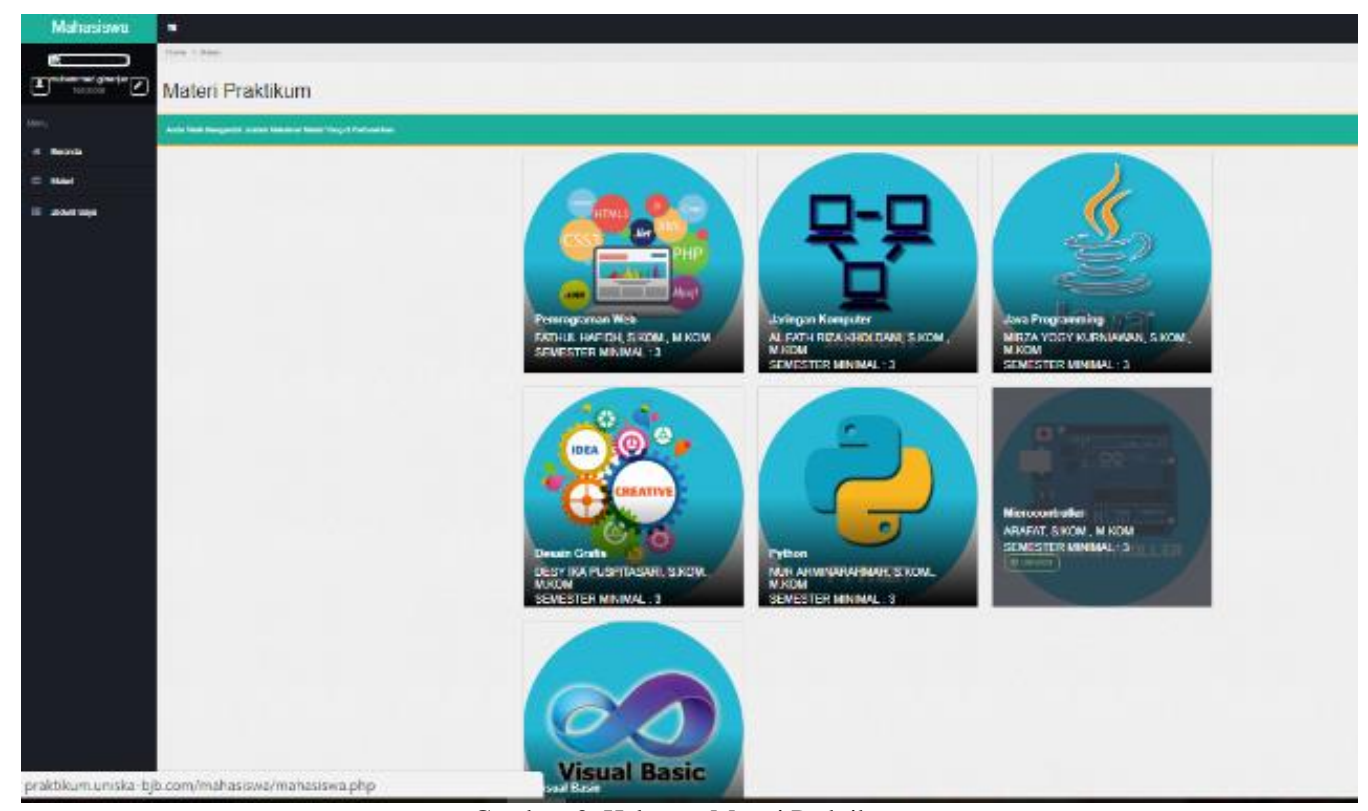

Gambar. 3. Halaman Materi Praktikum

\section{Login Dosen}

Fitur yang tersedia pada halaman dosen yaitu halaman memilih materi yang akan diajarkan, halaman jadwal dosen untuk membuat kelas dan jadwal praktikum dengan pilihan materi yang dipilih sebelumnya. Kemudian 
tersedia halaman cetak absensi untuk mencetak absensi sesuai jadwal dan kelas yang telah dibuat. Halaman dosen ditunjukkan pada Gambar 4.

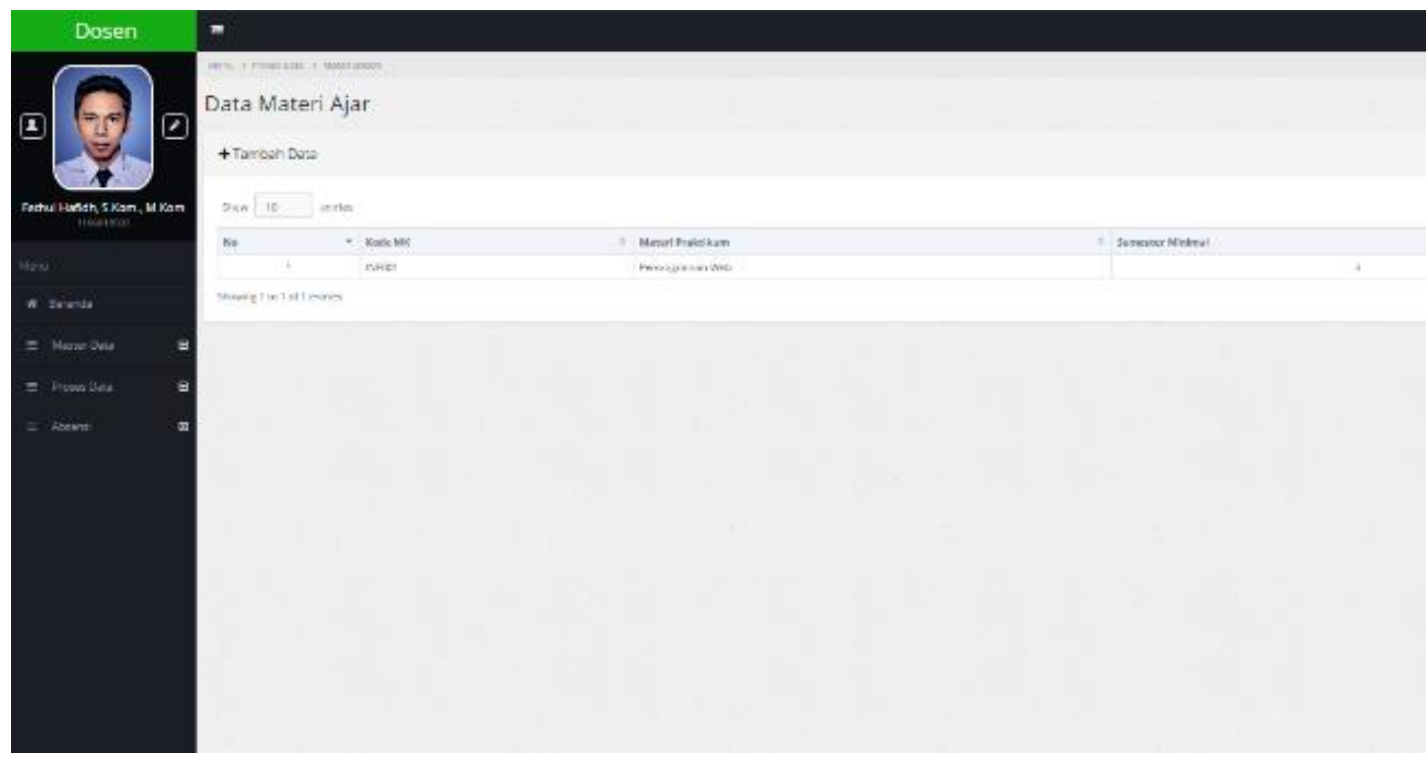

Gambar. 4. Data Materi Dosen

\section{Login Admin}

Fitur admin dapat merubah dan mengedit hampir seluruh data yang ada pada aplikasi, melihat dan merubah data mahasiswa, mengaktifkan status mahasiswa dan sebagainya. Halaman data dosen juga berfungsi mengaktifkan dosen juga merubah data dosen tersebut. Kemudian halaman berita yang berfungsi membuat berita atau pengumuman yang akan ditampilkan pada halaman utama. Halaman materi untuk membuat materi, mengaktifkan ataupun merubah data materi yang akan diberikan pada kegiatan praktikum. Halaman admin ditunjukkan pada Gambar 5.

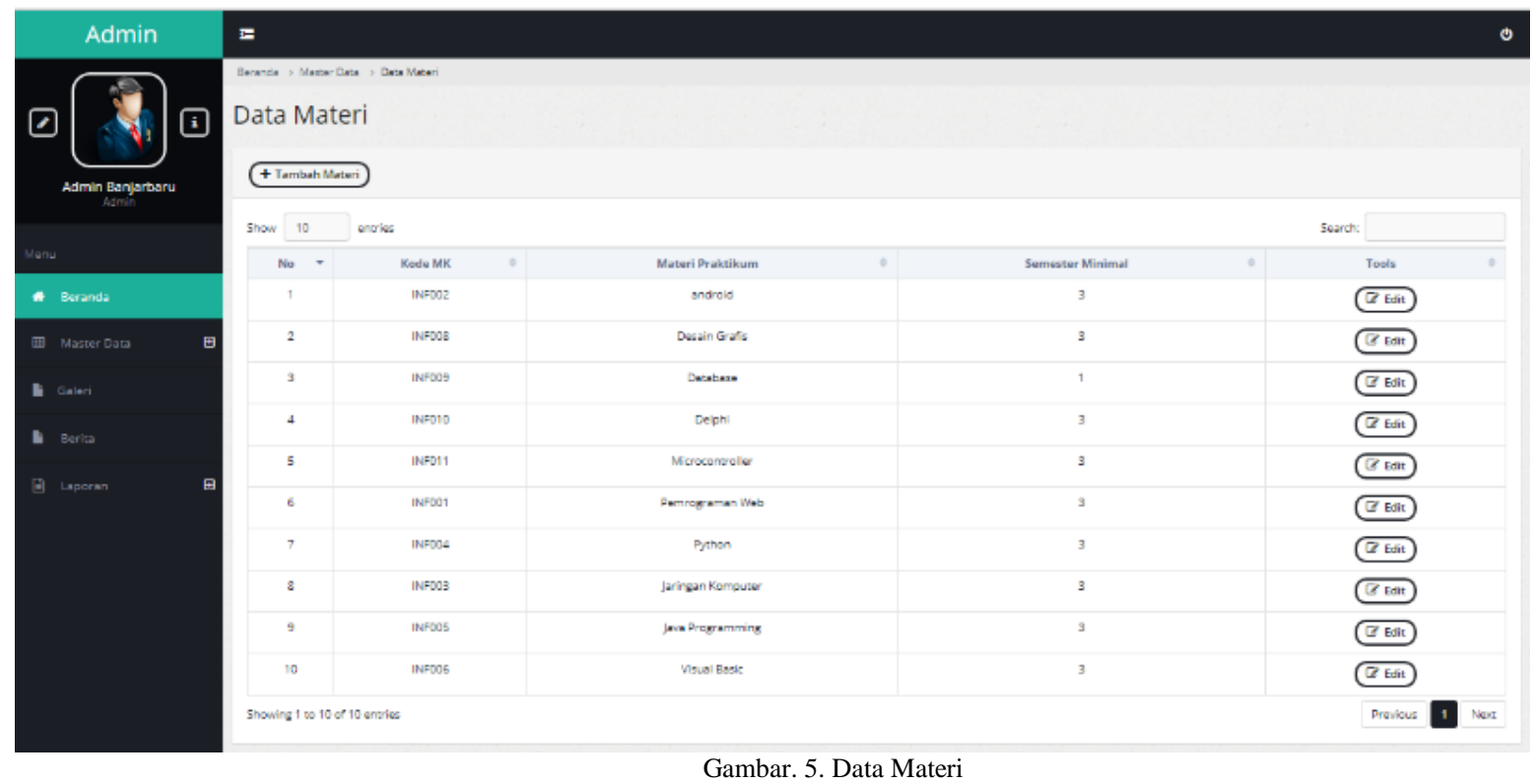

\section{B. Pembahasan}

Pengujian User Acceptance dilakukan pada penelitian ini agar mengetahui bahwa aplikasi yang telah dibuat ini layak atau masih memiliki banyak kekurangan. Pengujian User Acceptance ini menggunakan kuisioner 
JTIULM - Volume 03, Nomor 2, Oktober 2018: 47 - 52

yang diberikan kepada 15 responden berdasarkan model skala likert. Berdasarkan tabel dibawah yang didapatkan dari pengujian kuisioner, maka dapat disimpulkan bahwa aplikasi yang dibangun sudah sesuai dengan tujuan yaitu dapat mempermudah kegiatan praktikum.

\begin{tabular}{|c|c|c|c|c|c|c|c|}
\hline Tanggapan & Pertanyaan 1 & $\begin{array}{c}\text { Pertanyaan } \\
2\end{array}$ & Pertanyaan 3 & $\begin{array}{c}\text { Pertanyaan } \\
4\end{array}$ & $\begin{array}{c}\text { Pertanyaan } \\
5\end{array}$ & $\begin{array}{c}\text { Jumlah } \\
\text { presentase } \\
(\%)\end{array}$ & $\begin{array}{c}\text { Rata-Rata } \\
\text { Presentase } \\
(\%)\end{array}$ \\
\hline Sangat Setuju & $77.46 \%$ & $89.04 \%$ & $89.04 \%$ & $77.46 \%$ & $65.22 \%$ & $398.22 \%$ & $79.64 \%$ \\
\hline Setuju & $22.54 \%$ & $10.96 \%$ & $10.96 \%$ & $22.54 \%$ & $34.78 \%$ & $101.78 \%$ & $20.36 \%$ \\
\hline Cukup Setuju & $0.00 \%$ & $0.00 \%$ & $0.00 \%$ & $0.00 \%$ & $0.00 \%$ & $0.00 \%$ & $0.00 \%$ \\
\hline Todak Setuju & $0.00 \%$ & $0.00 \%$ & $0.00 \%$ & $0.00 \%$ & $0.00 \%$ & $0.00 \%$ & $0.00 \%$ \\
\hline Sangat Tidak Setuju & $0.00 \%$ & $0.00 \%$ & $0.00 \%$ & $0.00 \%$ & $0.00 \%$ & $0.00 \%$ & $0.00 \%$ \\
\hline Total & $100 \%$ & $100 \%$ & $100 \%$ & $100 \%$ & $100 \%$ & $500 \%$ & $100 \%$ \\
\hline
\end{tabular}

\section{PENUTUP}

Sistem yang dihasilkan adalah aplikasi penjadwalan praktikum yang membantu admin dalam mengelola kegiatan praktikum, membantu dosen dalam memilih materi, membuat jad wal dan mencetak absensi kegiatan praktikum serta membantu mahasiswa mendapatkan informasi dan kemudahan dalam memilih jadwal praktikum. Hasil pengujian black box kepada sistem menunjukkan bahwa fitur pada sistem sudah berjalan dengan baik. Hasil pengujian User Acceptence didapatkan bahwa sistem yang dibuat presentase dari seluruh pertanyaan adalah $79,64 \%$ sangat setuju dengan tingkat realibilitas sebesar 0.654 atau bernilai reliable.

\section{DAFTAR PUSTAKA}

[1] G. T. Sanjaya dan B. Sumboro, "Rancang Bangun Aplikasi Penjadwalan Kuliah STMIK AUB Surakarta Berbasis Web," GO INFOTECH, pp. $37-$ 42, 2015.

[2] Hamidah dan O. Rizan, “Sistem Informasi Penjadwalan Dosen Ajar,” TEKNOSI, pp. 65-74, 2016.

[3] W. Fatmawati, I. Sukendar dan P. Suryo, "Penjadwalan Kerja dengan Metode Algoritma Active Schedule dan Heuristic Schedule untuk Minimisasi Waktu Penyelesaian (Studi Kasus di PT. InTAC Brass Indonesia)," dalam Proceedings Seminar Nasional Teknologi Industri (SNT), Semarang, 2009.

[4] Z. Davis, "PC Magazine," 1907 2010. [Online]. Available: http://www.pcmag.com/encyclopedia/term/37919/application-program.

[5] D. P. Oktavian, Menjadi Programmer Jempolan dengan PHP, Yogyakarta: Mediakom, 2010. 